\title{
Alpha1-Adrenergic Receptors Mediate Bladder Overactivity Induced by Cold Stress in Rats with Bladder Outlet Obstruction
}

Takahiro Yamagishi ${ }^{1}$, Osamu Ishizuka ${ }^{1,2 *}$, Tetsuya Imamura ${ }^{2}$, Hitoshi Yokoyama ${ }^{1}$, Teruyuki Ogawa $^{1}$, Yoshiki Kurizaki ${ }^{1}$, Osamu Nishizawa ${ }^{1,2}$, and Karl-Erik Andersson ${ }^{3}$

${ }^{1}$ Department of Urology and ${ }^{2}$ Department of Lower Urinary Tract Medicine,

Shinshu University School of Medicine, Matsumoto, Japan

${ }^{3}$ Wake Forest Institute for Regenerative Medicine,

Wake Forest University School of Medicine, Winston Salem, NC, USA

* Correspondence:

Osamu Ishizuka, M.D., Ph.D.

Department of Urology, Shinshu University School of Medicine, 3-1-1 Asahi,

Matsumoto, Nagano, Japan

Tel.: +81-263-37-2661

FAX: $+81-263-37-3082$

e-mail: ishizuk@shinshu-u.ac.jp

Running head: Cold stress induces bladder overactivity in bladder outlet obstruction

Key Words: Alpha 1 -Adrenergic Receptors, Cold Stress, Bladder Outlet Obstruction, Rats, Overactive Bladder 


\begin{abstract}
Purpose: To determine if alpha1-adrenergic receptors (AR) mediate bladder overactivity induced by cold stress in rats with bladder outlet obstruction (BOO).

Materials and Methods: The urethras of 10-week-old female Sprague-Dawley rats were ligated to create BOO. After 4 weeks, cystometric investigations were performed at room temperature $\left(\mathrm{RT}, 27 \pm 2^{\circ} \mathrm{C}\right)$ for $20 \mathrm{~min}$. The rats were then given $0.3 \mathrm{mg} / \mathrm{kg}$ naftopidil $(n=6)$ or vehicle $(n=5)$ intravenously. Five minutes later, they were transferred to low temperature $\left(\mathrm{LT}, 4 \pm 2^{\circ} \mathrm{C}\right.$ ), and the cystometric patterns were again recorded for 40 min. In BOO rats and in sham-operated rats $(n=8)$ the expression levels of alpha $1 \mathrm{~A}^{-}$and alpha $\mathrm{D}_{1}-\mathrm{AR}$ mRNAs and the presence of alpha $\mathrm{1A}^{-}$and alpha $\mathrm{D}_{1}-\mathrm{AR}$ immunoreactivity on calcitonin gene-related peptide (CGRP)-positive nerve cells were investigated.
\end{abstract}

Results: During LT exposure, the vehicle-treated BOO rats exhibited cold stress-induced bladder overactivity. In the naftopidil-treated rats, the increase of basal pressure and decreases of both voiding interval and bladder capacity induced by LT were significantly reduced compared to the vehicle-treated animals. In the bladders of BOO rats exposed to LT, the expression of alpha ${ }_{1 D}-A R$ mRNA was significantly higher than in sham-operated rats, and the immunoreactivity for alpha $1 \mathrm{D}-\mathrm{ARs}$ on the CGRP-positive nerve cells tended to be more pronounced.

Conclusions: alpha1-ARs mediate part of the bladder overactivity induced by cold stress in rats with BOO. Cold stress increases the expression of alpha ${ }_{1 \mathrm{D}}-\mathrm{AR}$ mRNA and the immunoreactivity for alpha $\mathrm{1}_{\mathrm{D}}-\mathrm{ARs}$ on the CGRP-positive nerve cells in BOO rats. Naftopidil partially inhibits the cold stress overactivity, suggesting that it is mediated, at least partially, through alpha $1 \mathrm{D} / 1 \mathrm{~A}-\mathrm{ARs}$. 


\section{INTRODUCTION}

It is generally considered that in man cold stress, produced by seasonal or continuous environmental low temperature (LT), can elicit lower urinary tract symptoms (LUTS), including urinary urgency, frequency, and nocturia. Experimental animal data supporting this showed that normal rats exposed to cold stress, produced by sudden exposure to environmental low temperature (LT), showed bladder overactivity involving resiniferatoxin-sensitive C-fibers and alpha1-adrenoceptors (AR) ${ }^{1,2}$.

Benign prostatic hyperplasia (BPH), may lead to bladder outlet obstruction (BOO) and storage, voiding, and post-voiding symptoms. In rats with $\mathrm{BOO}$, it has been demonstrated that the obstruction-induced changes in the bladder wall are accompanied by neural plasticity resulting in a more prominent spinal reflex that could contribute to the development of bladder overactivity ${ }^{3,4}$, a change associated with an upregulated bladder C-fiber activity. Patients with neurogenic bladders may also have an upregulation of C-fiber mediated bladder activity ${ }^{5.6}$, and often have a positive ice water test $^{7}$, suggesting an enhanced sensitivity to cold. Since patients with BOO often have a positive ice water test ${ }^{8}$, there may be reasons to believe that also $\mathrm{BOO}$ can be associated with an enhanced LT-induced bladder overactivity.

In the present study, we have tested in a rat model of BOO 1) if sudden exposure to LT can induce bladder overactivity, 2) if such activity involves alpha1-ARs, and 3) whether sudden exposure to LT changes alpha1-AR expression (RT-PCR), or affects alpha1-AR immunoreactivity on afferent nerves. 


\section{MATERIAL AND METHODS}

\section{Animals}

Ten-week-old female Sprague-Dawley (SD) rats (Japan SLC Inc., Shizuoka, Japan) were used for the experiments. The animals were treated in accordance with National Institutes of Health Animal Care Guidelines and the guidelines approved by the Animal Ethics Committee of Shinshu University School of Medicine (No. 230047).

\section{Bladder Outlet Obstruction (BOO) Model}

SD rats were anesthetized with pentobarbital sodium solution $(40 \mathrm{mg} / \mathrm{kg}$-body weight, Kyoritsu Seiyaku Co., Tokyo, Japan), and then a midline incision was made to expose the urethra. To produce bladder outlet obstruction, a polyethylene tube (PE-50; inside diameter, $0.58 \mathrm{~mm}$; outside diameter, $0.97 \mathrm{~mm}$, Becton Dickinson and Company, Sparks, MD, USA) was placed adjacent to the urethra. Both the urethra and the tube were ligated with a 5-0 silk, and then the tube was carefully removed, leaving the ligature in place to create a mild BOO. Eight SD rats were subjected to sham operation without the ligature. All animals were kept for 4 weeks under a 12-hour alternating light-dark cycle with freely available food and water. To ascertain that the ligated rats were obstructed, only animals with a bladder capacity between 2 and $5 \mathrm{ml}$ at room temperature (RT) were selected for inclusion into the final BOO study group (age-matched, non-ligated SD rats have approximately 1-1.5 ml bladder capacity at RT). Ultimately, we accepted 11 of the ligated rats as meeting the above requirements for BOO for further studies.

\section{Drug}

Naftopidil, kindly provided by Asahi Kasei Pharma Co. (Tokyo, Japan), is an alpha1-AR blocker that has a high affinity for alpha1D/1A-ARs. The naftopidil powder was completely dissolved with $0.1 \mathrm{M}$ phosphate buffer solution in half of the final volume. Then several drops of $0.1 \mathrm{M}$ sodium dihydrogen phosphate solution were 
slowly added with vortexing and ultrasonication to achieve the final volume and $\mathrm{pH}, 4.0$. The dissolved naftopidil solution was diluted to desired concentration with $0.9 \%$ saline.

\section{Cystometric Investigations}

After 4 weeks, the surviving ligated rats were anesthetized as above to insert a catheter for cystometric investigations. Each urinary bladder and the ligated urethra was exposed and incised at the center of the dome. After releasing the urethral ligature, a polyethylene catheter (PE-50, Becton Dickinson and Company) was inserted through the incision and fixed at that site with a 5-0 suture. The free end was tunneled subcutaneously and exteriorized at the back of the neck. The cannulated rats were kept for 3 days as above. Just prior to the cystometric investigations, a polyethylene catheter (PE-10, Becton Dickinson and Company) was inserted into the jugular vein of the rats anesthetized by inhalation of 3\% sevoflurane (Abbot Japan Co., Ltd., Tokyo, Japan). Each rat was allowed to recover from the anesthesia in a metabolic cage for 2 hours. After recovery, the bladder catheter was connected through a T-tube to a pressure transducer (P23 DC; Nihon Kohden, Tokyo, Japan) and a syringe pump (TE-351, Terumo, Tokyo, Japan). A fluid collector connected to a force displacement transducer (Type 45196; NEC San-ei Instruments, Tokyo, Japan) to measure micturition volume was placed under the metabolic cage. Throughout the experiments, RT saline $\left(25-27^{\circ} \mathrm{C}\right)$ was pumped into the bladder at a rate of $10 \mathrm{ml} / \mathrm{hr}$. The bladder pressure and micturition volume were recorded continuously on a pen oscillograph $(10 \mathrm{~mm} / \mathrm{min}$ recording speed; Recti-Horiz-8K; NEC San-ei Instruments). The following cystometric parameters were measured: basal pressure $\left(\mathrm{cmH}_{2} \mathrm{O}\right)$, maximum pressure $\left(\mathrm{cmH}_{2} \mathrm{O} ;=\right.$ maximum pressure during the voiding cycle), voiding interval (min), micturition volume (ml), and bladder capacity $(\mathrm{ml})$. The bladder capacity was calculated by adding the micturition volume and the residual volume that was determined as the difference between the saline infusion volume and micturition volume. The rats were not given food or water during the cystometric investigations. 
Cystometric measurements of the catheterized, unanesthetized, unrestricted rats were taken under the following environmental temperature conditions. The rats were placed singly in metabolic cages at RT $\left(27 \pm 2^{\circ} \mathrm{C}\right)$ for 20 min and then intravenously administered $0.2 \mathrm{ml}$ of either $0.3 \mathrm{mg} / \mathrm{kg}$ naftopidil or vehicle, delivered slowly by hand-powered injection. After $5 \mathrm{~min}$, they were gently and quickly transferred to the metabolic cages in a cold room for LT exposure $\left(4 \pm 2^{\circ} \mathrm{C}\right)$ for $40 \mathrm{~min}$. After the cystometric investigations, the rats were anesthetized with pentobarbital sodium solution as above, and then the urinary bladders were removed. Afterwards, the rats were euthanized by inhalation of diethyl ether.

\section{Real-time RT-PCR}

We determined the effect of BOO on the expression of alpha $\mathrm{A}^{-}$and alpha $\mathrm{a}_{1}-\mathrm{AR}$ mRNA by real-time reverse-transcription polymerase chain reaction (RT-PCR). Approximately one third of the bladder tissue (from the bladder dome to the trigone) was homogenized, and total RNA was extracted with the RNeasy Mini Kit ${ }^{\circledR}$ (Qiagen Inc., Valencia, CA, USA). Complementary DNA (cDNA) was synthesized from $0.1 \mu \mathrm{g}$ of total RNA with the High Capacity RNA-to-cDNA Master Mix ${ }^{\circledR}$ (Life Technology Co. [Applied Biosystems], Foster City, CA, USA). The synthesized cDNA was mixed with $\operatorname{TaqMan}^{\circledR}$ Universal PCR Master Mix (Life Technology Co.) and TaqMan ${ }^{\circledR}$ gene expression assays (MGB probes, FAM ${ }^{\mathrm{TM}}$ dye-labeled, Life Technology Co.). The gene probes were alpha 1 A-AR (Adra1a, Rn00567876_m1, Life Technology Co.), alpha1D-AR (Adra1d, Rn00577931_m1, Life Technology Co.), and beta-actin (Actb, Rn00667869_m1, Applied Biosystems Co.). Real-time RT-PCR of the cDNA was performed by using the Opticon $2^{\circledR}$ PCR System and Opticon Monitor ver $3^{\circledR}$ (Bio-Rad Laboratories, Hercules, CA, USA). The reactions of the cDNA-probe mixed solution were performed at $50^{\circ} \mathrm{C}$ for $2 \mathrm{~min}$ followed by $95^{\circ} \mathrm{C}$ for $10 \mathrm{~min}$. These were followed by 40 cycles at $95^{\circ} \mathrm{C}$ for $15 \mathrm{sec}$ and $60^{\circ} \mathrm{C}$ for $1 \mathrm{~min}$. Gene expression was calculated by the delta-delta method as the relative ratio to threshold cycle value of the internal standard 
gene, beta-actin.

\section{Immunohistochemistry Investigations}

The harvested and trimmed urinary bladders were fixed in 4\% paraformaldehyde phosphate buffer solution (Nalkalai Tesque, Inc., Kyoto, Japan) for 12 hours at $4^{\circ} \mathrm{C}$. The tissues were embedded in paraffin, and cut into 5- $\mu \mathrm{m}$ thick serial sections. The sections were deparaffinized, and then antigen retrieval was achieved by immersion of the sections in 0.01 M sodium citrate ( $\mathrm{pH}$ 6.0, Mitsubishi Chemical Medience Co., Tokyo, Japan) and microwaving at $100^{\circ} \mathrm{C}$ for 5 minutes. The specimens were coated with $1.5 \%$ normal donkey serum (Chemicon International Inc., Temecula, CA, USA) and 1.5\% non-fat milk in $0.01 \mathrm{M}$ phosphate buffered saline (PBS, pH 7.4, Mitsubishi Chemical Medience Co.) for 1 hour at $4^{\circ} \mathrm{C}$. The sections were then incubated with the primary antibody for calcitonin gene-related peptide (CGRP, 1:800, guinea pig polyclonal, Progen Biotechnik GmbH, Heidelberg, Germany) as a marker of primary sensory neurons, and either alpha $1 \mathrm{~A}-\mathrm{AR}$ antibody (1:100, rabbit polyclonal, Santa Cruz Biotechnology Inc., CA, USA) or alpha 1 D-AR antibody (1:100, rabbit polyclonal, Santa Cruz Biotechnology Inc.) for 12 hours at $4^{\circ} \mathrm{C}$. The sections were rinsed with $\mathrm{PBS}$ at $4^{\circ} \mathrm{C}$, and then incubated with donkey anti-guinea pig IgG secondary antibody conjugated with Alexa Fluor 594 (1:250, Life Technology Co. [Molecular Probes], Eugene, OR, USA) and donkey anti-rabbit IgG secondary antibody conjugated with Alexa Fluor 488 (1:250, Life Technology Co.) for 1 hour at $4^{\circ} \mathrm{C}$. Following rinsing, cell nuclei were counterstained with $5 \mu \mathrm{g} / \mathrm{ml} \mathrm{4',6-diamidino-2-phenylindole} \mathrm{dihydrochloride} \mathrm{(DAPI,}$ Life Technology Co.). The slides were coated with Fluorescent Mounting Medium (Dako Cytomation, Carpinteria, CA, USA) and observed with a Leica DAS Microscopethe (Leica Microsystems GmbH, Wetzlar, Germany).

\section{Statistical Analysis}

The results were expressed as means \pm standard error of the means. Two-tail 
paired student's t-tests were used to compare values within each group. Two-tail unpaired student's t-tests were used between groups. Differences with $\mathrm{P}<0.05$ were considered significant. 


\section{RESULTS}

\section{Effects of Naftopidil on Cold Stress-induced Bladder Overactivity in BOO Rats}

Four weeks after urethral ligation and 3 days after bladder cannulation, the rats meeting the inclusion criteria of 2 to $5 \mathrm{ml}$ bladder capacity at RT were prepared for cystometric investigations at LT. The eleven $\mathrm{BOO}$ rats included were randomly separated into two groups. The naftopidil-treated group comprised 6 and the vehicle-treated group 5 rats. All BOO rats showed a mild bladder overactivity at baseline, with no differences between the groups (data not shown).

During LT exposure, vehicle-treated BOO rats exhibited enhanced bladder overactivity as shown by increased urinary frequency compared to RT (Fig. 1A). Naftopidil-treated rats also had LT-induced bladder overactivity (Fig. 1B); however, this was reduced compared to the vehicle-treated rats.

The basal pressure of the vehicle-treated rats at LT increased significantly, while maximum pressure did not change (Table 1). The voiding interval was reduced (from $18.75 \pm 1.82 \mathrm{~min})$ to $7.27 \pm 0.10 \mathrm{~min}(\mathrm{P}<0.01$ compared to RT, Fig. 1C), and the bladder capacity was reduced (from $3.12 \pm 0.52 \mathrm{ml}$ ) to $1.17 \pm 0.18 \mathrm{ml}(\mathrm{P}<0.01$ compared to RT, Fig. 1D). Similarly, during LT exposure, basal pressure of the naftopidil-treated rats also increased significantly, while maximum pressure did not change (Table 1). The voiding interval decreased (from $15.75 \pm 0.67 \mathrm{~min})$ to $9.29 \pm 0.99 \min (\mathrm{P}<0.01$ compared to $\mathrm{RT}$, Fig. 1C), and bladder capacity decreased (from $2.60 \pm 0.13 \mathrm{ml}$ ) to $1.51 \pm 0.13 \mathrm{ml}(\mathrm{P}<0.01$ compared to RT, Fig. 1D).

As mentioned, there were no differences between the vehicle- and naftopidil-treated rats in micturition parameters at RT. However, the increase of basal pressure and decreases of voiding interval and bladder capacity due to LT exposure in the naftopidil-treated rats were significantly reduced compared to the vehicle-treated rats (Table 1, Fig. 1C and D).

\section{Expression Level of alpha1-AR mRNAs and Presence of alpha1-ARs in BOO Rats}


To investigate the effects of naftopidil on cold stress-induced bladder overactivity, we semi-quantitatively estimated alpha 1 -AR mRNAs within the urinary bladder tissues. The expression level of alpha $1 \mathrm{~A}-\mathrm{AR}$ mRNA in the BOO rats was similar to the sham-operated rats (Fig. 2A). However, the expression level of alpha $1 \mathrm{D}-\mathrm{AR}$ mRNA in the BOO rats was significantly higher than that in the sham-operated rats (Fig. 2B).

The alpha $1 \mathrm{~A}-\mathrm{AR}$ immunoreactivity on the CGRP-positive nerve cells in the sham-operated rats (Fig. 2C) was similar to that in the BOO rats (Fig. 2D). Both sham-operated and BOO rats also exhibited alpha 1 D-ARs on the CGRP-positive cells (Fig. 2E and F, respectively); however, there appeared to be more in the BOO rats compared to the sham-operated rats. Alpha 1 -ARs were also present on cells other than the CGRP-positive neurons and also appeared to be present in greater numbers in the BOO rats. This was consistent with the higher expression levels of alpha 1 -AR mRNAs in the bladders of these animals. 


\section{DISCUSSION}

This study showed that rats with BOO and bladder capacities between 2 and $5 \mathrm{ml}$, exhibited cold stress-induced bladder overactivity when exposed to LT. During LT exposure, basal pressure increased significantly, and both voiding interval and bladder capacity decreased significantly compared to the RT baselines.

It has previously been shown that in normal rats, cold stress-induced bladder overactivity can be reduced, but not eliminated, by administration of alphat-AR $\operatorname{antagonists}^{1,2}$, and this was demonstrated to be the case also in $\mathrm{BOO}$ rats. Thus, the increased basal pressure and decreased voiding interval and bladder capacity found in these animals were significantly reduced by naftopidil. However, in separate preliminary studies, it was shown that in $\mathrm{BOO}$ rats with bladder capacities greater than $5 \mathrm{ml}$, alpha1-AR antagonists had no effect on cold stress-induced bladder overactivity (data not shown). While the reason for this refractoriness has not yet been investigated, it suggests that the effectiveness of alpha 1 -AR antagonists might be dependent on the degree of obstruction-induced changes in the bladder wall and consequent effects on neuronal plasticity. It also suggests that factors besides alpha1-ARs may contribute. In previous studies 9,10 we determined if transient receptor potential melastatin 8 (TRPM8) channels were involved in the bladder overactivity induced by exposure to LT. It was found that the TRPM8 channel agonist, BCTC, effectively inhibited LT-induced bladder overactivity, and concluded that TRPM8 channels together with alpha1-ARs mediated this activity. Other factors for the incomplete response to the alpha1-AR antagonists that needs to be taken into consideration are that 1) the optimum concentration of naftopidil to completely inhibit the cold stress-induced bladder overactivity was not established, and 2) we did not explore the possibility that naftopidil caused an improvement of microcirculation in the bladder. Impeded blood flow is one of the mechanisms of bladder overactivity in BOO rats ${ }^{11,12}$, and alpha1-AR antagonists improve storage function due to reduction of the impediment to blood flow ${ }^{13,14}$.

Alpha1-ARs are subdivided into three subtypes: alpha $1_{1-}^{-}$, alpha $1_{1}{ }^{-}$and 
alpha 1 D-AR ${ }^{15}$. The alpha 1 -ARs expressed within the lower urinary tract mediate functions related to neurotransmission and endocrine responses ${ }^{16}$. A number of experimental studies showed that antagonism of alpha $1 \mathrm{D}-\mathrm{AR}$ in the bladder, urothelium, prostate, peripheral ganglia, and spinal cord improves urinary storage ${ }^{17,18,19}$. Thus, the antagonists of these alpha ${ }_{1}$-ARs improve not only voiding symptoms, but also storage symptoms in patients with BPH.

Alpha1-ARs play important roles in the activation of afferent pathways ${ }^{18,19,20,21}$, and we have previously shown that cold stress-induced bladder overactivity was mediated by resiniferatoxin-sensitive nerves that express CGRP ${ }^{1}$. Thus, to investigate the mechanisms involved in the LT-induced overactivity, we focused on the expression of alpha $a_{1}$-AR mRNAs within the urinary bladders and the presence alpha1-AR immunoreactivity on the CGRP-positive nerves. Prior to these investigations, we confirmed that a single administration of vehicle or $1.0 \mathrm{mg} / \mathrm{kg}$ naftopidil did not change the expression level of mRNAs or receptors within urinary bladder tissues (data not shown).

The expression level of alpha $1 \mathrm{~A}-\mathrm{AR}$ mRNA in the BOO rats was the same as that in the sham-operated rats with intact urinary bladders. However, the expression level of alpha $1 \mathrm{D}-\mathrm{AR}$ mRNA in the BOO rats was significantly higher than that in the sham-operated rats. Alpha1-AR immunoreactivity was demonstrated on bladder CGRP-positive primary sensory neurons of both BOO and sham-operated rats. The immunoreactivity for alpha $\mathrm{A}_{\mathrm{A}}-\mathrm{ARs}$ in the $\mathrm{BOO}$ rats were similar to that the sham-operated rats. In contrast, the presence of alpha $1 \mathrm{D}-\mathrm{AR}$ immunoreactivity on the BOO rat CGRP-positive nerves tended to be greater than that in the sham-operated rats. Further studies are required to establish with certainty the differences in distribution of these receptors in $\mathrm{BOO}$ and sham-operated rats.

Even with the limitations of this study, we have shown that the cold stress-induced bladder overactivity of the BOO rats is mediated, at least in part, through alpha 1 -ARs, particularly the alpha $1 \mathrm{D}-\mathrm{AR}$. It may be speculated that the alpha $1 \mathrm{D} / 1 \mathrm{~A}-\mathrm{AR}$ antagonist, 
naftopidil may have the potential to improve storage symptoms exacerbated by cold stress in patients with $\mathrm{BPH}$. 


\section{CONCLUSION}

In rats with $\mathrm{BOO}$ sudden exposure to LT can induce bladder overactivity. This activity involves alpha1-ARs and can be partly reduced by the alpha $1 \mathrm{D} / \mathrm{A}-\mathrm{AR}$ antagonist,

naftopidil. In BOO rats, sudden exposure to LT increases alpha1D-AR expression and alpha1D-AR immunoreactivity on afferent nerves. 


\section{REFERENCES}

1. Imamura T, Ishizuka O, Aizawa N, et al. Cold environmental stress induces bladder overactivity via resiniferatoxin-sensitive nerves in conscious rats. Neurourol Urodyn 2008; 27: 348-52.

2. Chen Z, Ishizuka O, Imamura $\mathrm{T}$, et al. Role of alpha1-adrenergic receptors in bladder overactivity induced by cold stress in conscious rats. Neurourol Urodyn 2009; 28: 251-6.

3. Steers WD, De Groat WC. Effect of bladder outlet obstruction on micturition reflex pathways in the rat. J Urol 1988; 140: 864-71.

4. Steers WD, Ciambotti J, Erdman S, et al. Morphological plasticity in efferent pathways to the urinary bladder of the rat following urethral obstruction. J Neurosci. 1990 Jun; 10: 1943-51.

5. Fowler CJ. Bladder afferents and their role in the overactive bladder. Urology. 2002 May; 59(5 Suppl 1): 37-42.

6. de Groat WC, Yoshimura N. Changes in afferent activity after spinal cord injury. Neurourol Urodyn. 2010; 29: 63-76.

7. Fall M, Geirsson G. Positive ice-water test: a predictor of neurological disease? World J Urol. 1996;14 Suppl 1:S51-4.

8. Chai TC, Gray ML, Steers WD. The incidence of a positive ice water test in bladder outlet obstructed patients: evidence for bladder neural plasticity. J Urol. 1998 Jul; 160: $34-8$.

9. Lei Z, Ishizuka O, Imamura T, et al. Functional roles of transient receptor potential melastatin 8 (TRPM8) channels in the cold stress-induced detrusor overactivity pathways in conscious rats. Neurourol Urodyn. 2013 Jun; 32: 500-4.

10. Noguchi W, Ishizuka O, Imamura T, et al. The relationship between alpha1-adrenergic receptors and TRPM8 channels in bladder overactivity induced by cold stress in ovariectomized rats. J Urol 2013; 189: 1975-81.

11. Matsumoto S, Uemura H. Examination of the mechanism of ameliorating effect of alpha 1-blocker on storage symptoms associated with benign prostatic hyperplasia. Hinyokika Kiyo 2008; 54: 453-6.

12. Pinggera GM, Mitterberger M, Steiner E, et al. Association of lower urinary tract symptoms and chronic ischaemia of the lower urinary tract in elderly women and 
men: assessment using color Doppler ultrasonography. BJU Int 2008; 102: 470-4.

13. Okutsu H, Matsumoto S, Ohtake A, et al. Effect of tamsulosin on bladder blood flow and bladder function in a rat model of bladder over distention/emptying induced bladder overactivity. J Urol 2011; 186: 2470-7.

14. Mine S, Yamamoto T, Mizuno H, et al. Effect of tamsulosin on bladder microcirculation in rat model of bladder outlet obstruction using pencil lens charge-coupled device microscopy system. Urology 2013; 81: 155-9.

15. Michel MC, Kenny B, Schwinn DA. Classification of alpha 1-adrenoceptor subtypes. Naunyn Schmiedebergs Arch Pharmacol 1995; 352: 1-10.

16. Andersson KE, Gratzke C. Pharmacology of alpha1-adrenoceptor antagonists in the lower urinary tract and central nervous system. Nat Clin Pract Urol. 2007 Jul; 4: $368-78$.

17. Yokoyama O, Yusup A, Oyama N, et al. Improvement in bladder storage function by tamsulosin depends on suppression of C-fiber urethral afferent activity in rats. $\mathrm{J}$ Urol 2007; 177: 771-5.

18. Kim JH, Shim JS, Kang SC, et al. Effects of spinal and peripheral injection of $\alpha 1 \mathrm{~A}$ or $\alpha 1 \mathrm{D}$ adrenoceptor antagonists on bladder activity in rat models with or without bladder outlet obstruction. Int Neurourol J 2011; 15: 199-205.

19. Yazaki J, Aikawa K, Shishido K, et al. Alpha1-adrenoceptor antagonists improve bladder storage function through reduction of afferent activity in rats with bladder outlet obstruction. Neurourol Urodyn 2011; 30: 461-7.

20. Ishihama $\mathrm{H}$, Momota $\mathrm{Y}$, Yanase $\mathrm{H}$, et al. Activation of alpha1D adrenergic receptors in the rat urothelium facilitates the micturition reflex. J Urol 2006; 175: 358-64.

21. Yanase H, Wang X, Momota Y, et al. The involvement of urothelial alpha1A adrenergic receptor in controlling the micturition reflex. Biomed Res 2008; 29: 239-44. 


\section{Figure Legends}

Figure 1. Micturition patterns with change from RT to LT. A: After transfer to LT, the vehicle-treated $\mathrm{BOO}$ rats exhibited cold stress-induced bladder overactivity patterns including increased micturition frequency (upper tracing) and decreased of micturition volume (lower tracing). B: Naftopidil-treated BOO rats transferred to LT also exhibited the cold stress-induced bladder overactivity. The cold responses were reduced compared to vehicle-treated rats. Top: bladder pressure; Bottom: micturition volume. $\mathbf{C}$ and D: During LT exposure, voiding interval (C) and bladder capacity (D) of both vehicle- and naftopidil-treated BOO rats were significantly decreased. However, the decrease of these values in the naftopidil-treated rats was significantly less compared to the vehicle-treated ones. White bar: RT, black bar: LT. ${ }^{* *} \mathrm{P}<0.01$; compared to RT baseline values. $\dagger \mathrm{P}<0.05$; compared to vehicle-treated rats.

Figure 2. Alpha $\mathrm{A}_{\mathrm{A}}$ - and alpha $\mathrm{D}_{\mathrm{D}}-\mathrm{AR} \mathrm{mRNA}$ and protein expression within the urinary bladders. A and B: The relative expression of (A) alpha $1_{A^{-}}$and (B) alpha $\mathrm{D}-\mathrm{AR}$ mRNA in the urinary bladders. The expression level of alpha ${ }_{1 \mathrm{~A}}-\mathrm{AR}$ mRNA in BOO rats was the same as in sham-operated rats with intact urinary bladders. However, the expression level of alpha $\mathrm{D}_{\mathrm{D}}-\mathrm{AR}$ mRNA in the BOO rats was significantly higher than in the sham-operated rats. ${ }^{*} \mathrm{P}<0.01$, compared to the sham rats. $\mathbf{C}$ and $\mathbf{D}$ : For each triad of images, the alpha $1_{\mathrm{A}}$-ARs (green) are in the upper left micrograph, the CGRP-positive nerve cells (red) are in the lower left micrograph, and the merged images are in the larger micrograph to the right side of each group. There was no difference between the sham-operated (arrows, C) and BOO (arrows, D) rats in the presence of alpha 1 A-ARs within the CGRP-positive nerve cells. $\mathbf{E}$ and F: For each triad of images, the alpha $1 \mathrm{D}-A R s$ (green) are in the upper left micrograph, the CGRP-positive nerve cells (red) are in the lower left micrograph, and the merged images are in the larger micrograph to the right side of each group. The expression of alpha ${ }_{1 \mathrm{D}}$-ARs within the CGRP-positive nerve cells in the BOO rats (arrows, F) tended to higher compared to the sham-operated rats (arrow, E). Bar: $20 \mu \mathrm{m}$. Blue: nuclei. 


\section{Abbreviations and Acronyms}

$\mathrm{LT}=$ low temperature

$\mathrm{RT}=$ room temperature

$\mathrm{AR}=$ adrenergic receptor

LUTS $=$ lower urinary tract symptoms

$\mathrm{BPH}=$ benign prostatic hyperplasia

$\mathrm{QOL}=$ quality of life

$\mathrm{BOO}=$ bladder outlet obstruction

RT-PCR $=$ reverse transcription polymerase chain reaction

$\mathrm{CGRP}=$ calcitonin gene-related peptide 
Table 1. Effects of temperature and naftopidil on basal and micturition pressures in BOO rats

$$
\text { RT }
$$

LT

Basal pressure $\left(\mathrm{cmH}_{2} \mathrm{O}\right)$

$\begin{array}{rcc}\text { vehicle-treated } & 10.77 \pm 3.49 & 21.63 \pm 4.23^{*} \\ \text { naftopidil-treated } & 4.83 \pm 0.54 & 10.81 \pm 1.49 * \dagger\end{array}$

Micturition pressure $\left(\mathrm{cmH}_{2} \mathrm{O}\right)$

$\begin{array}{rrr}\text { vehicle-treated } & 37.37 \pm 7.68 & 40.37 \pm 7.84 \\ \text { naftopidil-treated } & 31.40 \pm 5.50 & 33.34 \pm 4.51\end{array}$

RT, room temperature; LT, low temperature; ${ }^{*} \mathrm{P}<0.01$; compared to RT in each group; $\uparrow \mathrm{P}<0.05$; compared to vehicle-treated rats; vehicle-treated rats, $n=5$; naftopidil-treated rats, $n=6$. 


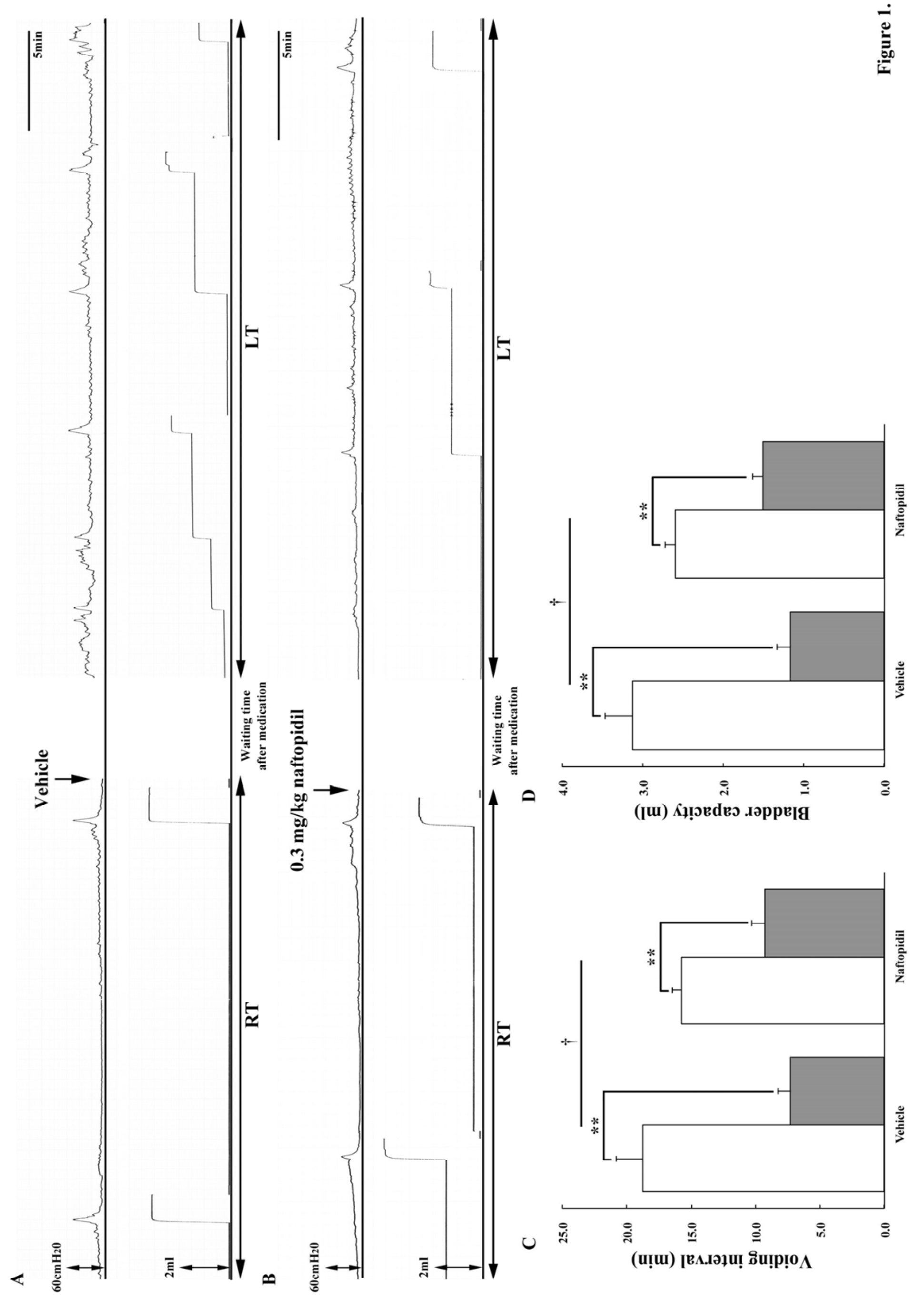



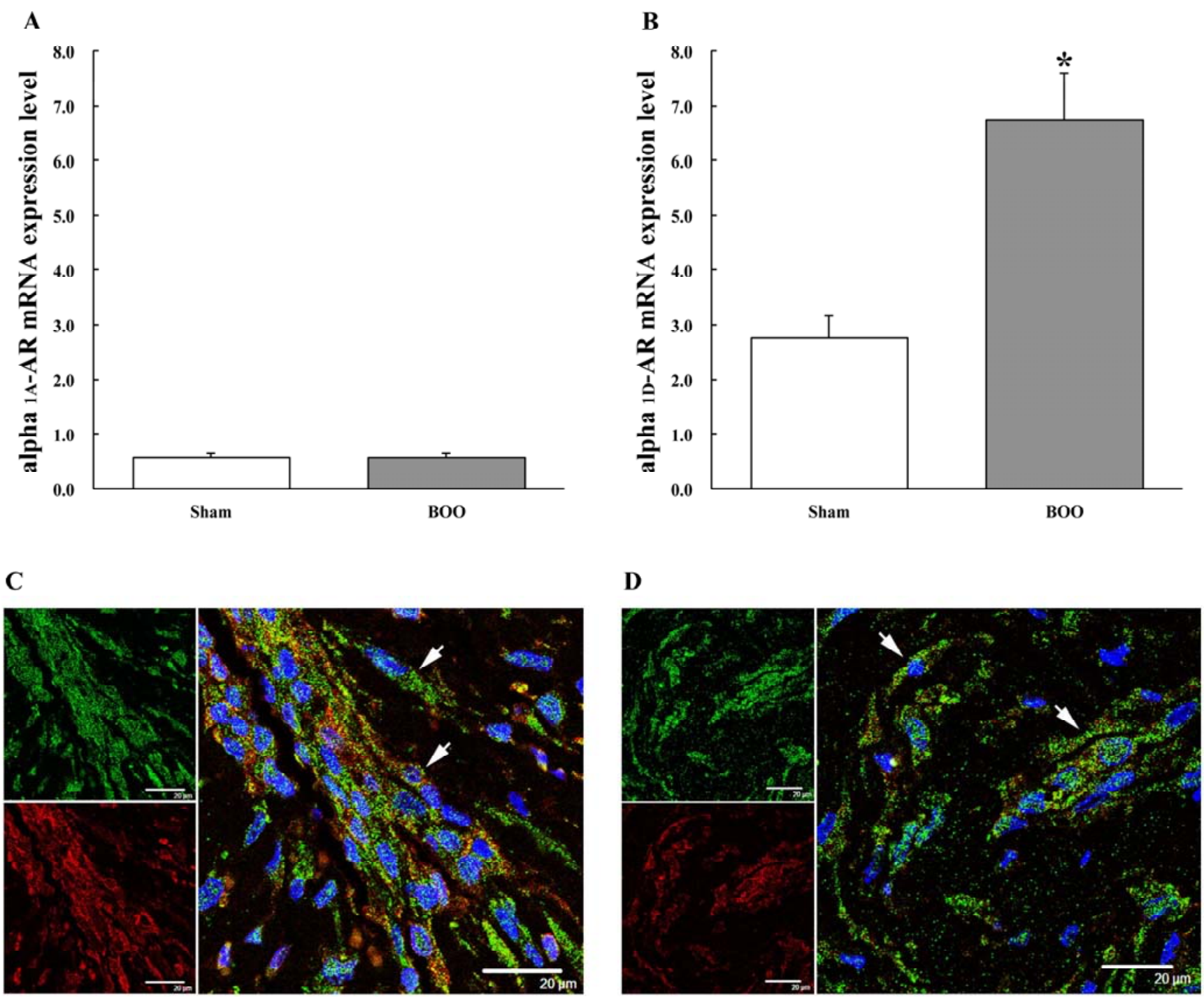

E

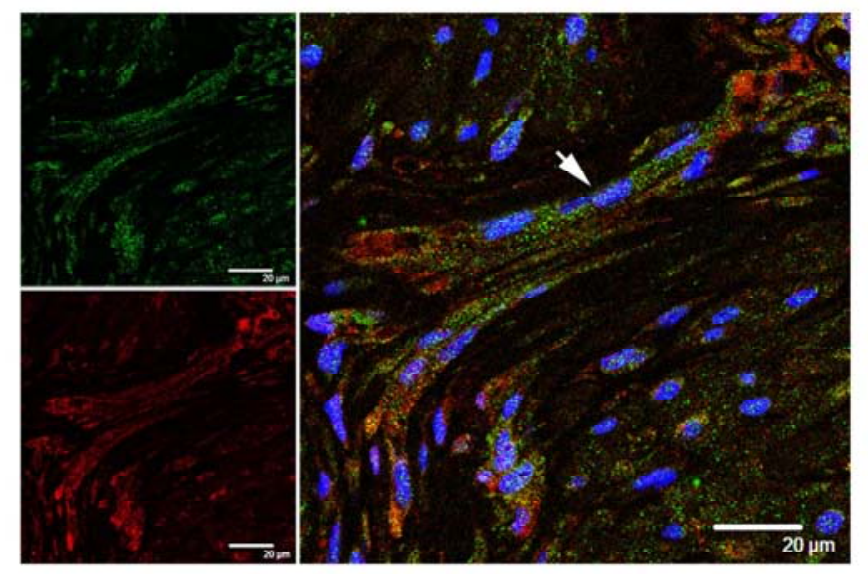

F

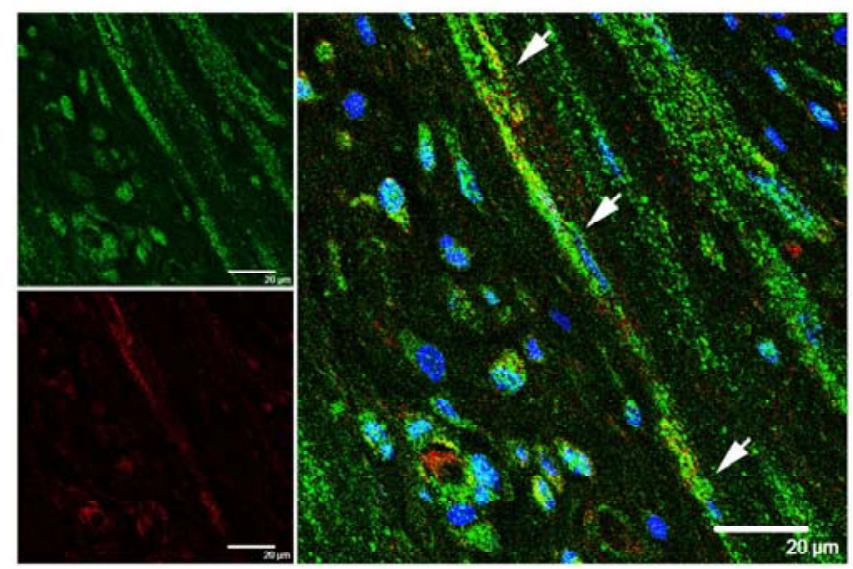

Figure 2. 